\title{
Correlation between Noncompliance Behavior and Biochemical Parameters of Chronic Kidney Disease Patients Undergoing Hemodialysis
}

\author{
Sarita Telma Fernandes ${ }^{1}$ Sushma Marita Dsouza ${ }^{2}$ \\ ${ }^{1}$ Department of Community Health Nursing, Nitte Usha Institute of \\ Nursing Sciences, Deralakatte, Mangalore, Karnataka, India \\ 2 Access Health International, Delhi, India \\ J Health Allied Sci ${ }^{\mathrm{NU}}$ 2022;12:258-262.
}

\begin{abstract}
Address for correspondence Sushma Marita Dsouza, MPH, Access Health International, House No. 275, Behind Bank of India, Shri Ram Nagar, G.T. Road, Shahdara, East Delhi, Delhi 110032, India (e-mail: sushmadsouza22@gmail.com).
\end{abstract}

\author{
Abstract \\ Keywords \\ - biological parameter \\ - chronic kidney \\ disease \\ - corelation \\ - hemodialysis \\ - noncompliance \\ behavior
}

Background and Objectives Compliance with dietary, fluid, and medication instructions is a critically significant factor for the health and well-being of patients undergoing hemodialysis for an extended period. The current study assessed the correlation between noncompliance behavior and biochemical parameters of chronic kidney disease (CKD) patients undergoing hemodialysis. The study's objectives were 1) to assess patients' noncompliance behavior using a questionnaire, 2) to determine the biochemical parameters of CKD patients having noncompliance behavior, and 3 ) to find the correlation between biological parameters and noncompliance behavior.

Methods A cross-sectional study was conducted from July 12, 2018, to February 10 , 2019. A purposive sampling technique was used to recruit the participants, and 100 participants were included in the study. The End-Stage Renal Disease-Adherence Questionnaire was used to assess the non-compliance behavior.

Results Most dialysis patients (70\%) were compliant with the therapeutic regime, while $30 \%$ failed to comply. The study revealed a significant positive correlation between noncompliance behavior and biochemical parameters of CKD patients undergoing hemodialysis $(r=0.578, p<0.05)$.

Conclusion Noncompliance behavior is significantly correlated with the biochemical parameters among patients with CKD on dialysis. Optimal health is possible through fluid and dietary compliance in these patients. Hence, adherence behavior plays a significant role in the health and recovery of dialysis patients with CKD.

\section{Introduction}

In the body, healthy kidneys purify the blood and eliminate the extra fluid and the waste in the form of urine. Moreover, they keep our bodies healthy. Chronic kidney disease (CKD) is a slowly progressive disease of kidney function, character- ized by a low glomerular filtration rate (GFR). ${ }^{1}$ When kidneys fail to function, dialysis performs its function as replacement therapy for kidney failure. It involves eliminating waste products such as creatinine and urea and free water from the blood when the kidneys do not work regularly. ${ }^{2}$ published online

December 31, 2021
DOI https://doi.org/ $10.1055 / \mathrm{s}-0041-1740023$ ISSN 2582-4287.

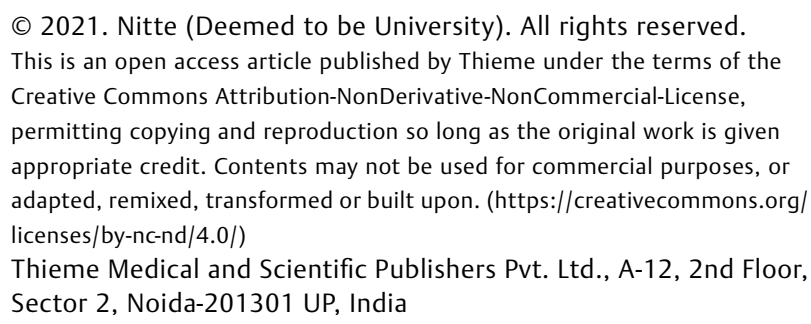


Hemodialysis is an intensive and expensive therapy and requires strict fluid and dietary restrictions. Consequently, repeated dialysis leads to a personal and financial burden to the person and their families. ${ }^{3}$ Even with the unceasing development of dialysis technology and pharmacological treatment, mortality rates are still high for dialysis patients. In India, nearly 9 to $13 \%$ of patients undergoing hemodialysis die within 1 year. Along with dialysis adequacy, the noncompliance behavior also affects the patient's survival in hemodialysis. $^{4}$

Noncompliance is common among patients undergoing hemodialysis. Furthermore, noncompliance behavior varies from patient to patient with different treatment regimens which includes adherence to drugs, fluid, treatment, and dietary restrictions. ${ }^{5-7}$ Failure to adhere to dietary restriction leads to faster progression of kidney disease into kidney failure and eventually results in kidney transplants. The shreds of evidence from studies show that failure to comply with dietary restrictions relates to renal disease progression. ${ }^{8}$

When CKD patients start hemodialysis, their entire life changes; they should regularly travel to dialysis centers to take prescribed medications without fail, and they have to modify their dietary patterns. The successful treatment of renal disease will largely depend on the patient's adherence behavior. ${ }^{9,10}$

The most common data sources that indicate adherence to medications and restrictions on diet and fluid intake are serial values of the biochemical index, which have straight implications on health outcomes. ${ }^{11}$ The often-used parameters are interdialytic weight gain (IWG), as an indicator of fluid compliance, predialysis blood urea nitrogen (BUN), and serum potassium (K) as measures of dietary compliance and serum phosphate $\left(\mathrm{PO}_{4}\right)$ as a parameter for medication compliance. ${ }^{12,13}$ As compared with other compliance measures, such as patient self-reports and staff reports, these parameters are generally considered to be more consistent, less biased, and objective. ${ }^{14,15}$

The current study was conducted to assess patients' noncompliance behavior with regard to medication, fluid, diet, and dialysis and determine the biochemical variations in patients with noncompliance behavior and its correlation. Here, noncompliance is referred to as failure to maintain the dietary, drugs, and fluid restrictions prescribed for the CKD patients undergoing hemodialysis.

\section{Materials and Methods}

\section{Study Design and Participants}

A cross-sectional study was conducted among 100 dialysis patients (universal samples) who fulfilled the inclusion criteria. Subjects were selected from three different settings namely a tertiary care hospital in Mangaluru comprising 12 dialysis beds, dialysis centers in Karkala ( 6 beds) and Puttur ( 5 beds). The study's inclusion criteria were CKD patients aged 18 years and above, undergoing hemodialysis for more than 3 months, and screened for noncompliance behavior. The study's exclusion criteria were patients undergoing hemodialysis for the first time and critically ill patients.

\section{Sample Size Calculation}

The sample size was calculated using the statistical formula for estimating a single proportion. It was expected that $50 \%$ of CKD patients undergoing dialysis were noncompliant with dietary and fluid restriction with $10 \%$ relative precision with a $95 \%$ confidence interval. The estimated sample size was $n=100$.

\section{Ethical Consideration}

The study was reviewed and approved on April 20, 2018, by the Institutional Review and Ethics Committee. The registration number was NUINS/CON/NU/IEC/2018-19. A subject information sheet was provided with a clear explanation about the study purpose and written informed consent was obtained before including the study participants. Confidentiality was assured to the entire subjects. They were instructed to sign the consent form, fill the demographic proforma, and End-Stage Renal Disease-Adherence Questionnaire (ESRDAQ).

\section{Instruments}

The following tools were used to collect the data: (1) demographic proforma, which comprised 10 items such as age, gender, religion, educational status, marital status, family income, diagnosis of the sample, duration of dialysis, and the number of times he/she has undergone hemodialysis; (2) ESRD-AQ questionnaire, which refers to the End-Stage Renal Disease-Adherence Questionnaire. It is a standardized tool developed to test the treatment adherence of people undergoing hemodialysis; hemodialysis attendance, medications, fluid restrictions, and diet prescription. ${ }^{16}$

\section{Data Collection}

A purposive sampling technique was used to recruit the participants to the study. Formal written permission was obtained from the Medical Superintendent of the respective hospital and dialysis centers. The data collection period was from July 12, 2018, to February 10, 2019. Homogenous time sessions were followed for the data collection.

\section{Data Analysis}

The data were analyzed using Statistical Package for Social Sciences 20 (SPSS 20) software. The data were analyzed in terms of objectives and hypotheses of the study using both descriptive and inferential statistics. Data on noncompliance behavior and biochemical parameters are expressed in frequency and percentage. Pearson's correlation coefficient $(r)$ was used to find the relationship between biochemical parameters and noncompliance behavior. A $p$-value $<0.05$ was considered significant.

\section{Results}

A total of 100 patients were selected for the study. The mean age of the patients was $54.15 \pm 14.29$ (standard deviation [SD]). The distribution of subjects based on gender revealed that most dialysis patients were males (77\%). The majority of dialysis patients had high school education (63\%), 15\% had 
Table 1 Distribution of demographic characteristics

\begin{tabular}{|c|c|c|}
\hline Variables $(n=100)$ & Frequency $(n)$ & Percentage (\%) \\
\hline $\begin{array}{l}\text { Age }(y) \\
<20 \\
20-50 \\
>50\end{array}$ & $\begin{array}{l}1 \\
42 \\
57\end{array}$ & $\begin{array}{l}1 \\
42 \\
57\end{array}$ \\
\hline $\begin{array}{l}\text { Gender } \\
\text { Male } \\
\text { Female }\end{array}$ & $\begin{array}{l}77 \\
23\end{array}$ & $\begin{array}{l}77 \\
23\end{array}$ \\
\hline $\begin{array}{l}\text { Religion } \\
\text { Hindu } \\
\text { Muslim } \\
\text { Christian }\end{array}$ & $\begin{array}{l}79 \\
11 \\
10\end{array}$ & $\begin{array}{l}79 \\
11 \\
10\end{array}$ \\
\hline $\begin{array}{l}\text { Education } \\
\text { Primary school } \\
\text { High school } \\
\text { Pre-degree } \\
\text { Diploma } \\
\text { Graduate }\end{array}$ & $\begin{array}{l}11 \\
63 \\
15 \\
6 \\
6\end{array}$ & $\begin{array}{l}11 \\
63 \\
15 \\
6 \\
6\end{array}$ \\
\hline $\begin{array}{l}\text { Marital status } \\
\text { Single } \\
\text { Married } \\
\text { Divorced } \\
\text { Widow }\end{array}$ & $\begin{array}{l}6 \\
84 \\
1 \\
9\end{array}$ & $\begin{array}{l}6 \\
84 \\
1 \\
9\end{array}$ \\
\hline $\begin{array}{l}\text { Family income } \\
<5000 \\
5000-10000 \\
>10000\end{array}$ & $\begin{array}{l}17 \\
50 \\
33\end{array}$ & $\begin{array}{l}17 \\
50 \\
33\end{array}$ \\
\hline $\begin{array}{l}\text { Duration of } \\
\text { hemodialysis } \\
<1 \mathrm{y} \\
1-5 \mathrm{y}\end{array}$ & $\begin{array}{l}33 \\
67\end{array}$ & $\begin{array}{l}33 \\
67\end{array}$ \\
\hline $\begin{array}{l}\text { Diagnosis } \\
\text { CKD }\end{array}$ & 100 & 100 \\
\hline No of dialysis per week & 100 & 100 \\
\hline
\end{tabular}

Abbreviation: $n=$ number.

pre-degree education, $11 \%$ had primary school education, $6 \%$ had diploma education, and $6 \%$ had graduate education.

The distribution of subjects based on marital status revealed that most dialysis patients were married (84\%), $9 \%$ were widows, and $6 \%$ were single. Based on family income, the distribution revealed that the majority (50\%) had an income between 5,000 to 10,000 . With regard to dialysis treatment duration, most dialysis patients (67\%) underwent dialysis for a period of 1 to 5 years. The distribution of subjects based on the number of dialysis per week revealed that $100 \%$ of dialysis patients were undergoing dialysis twice a week ( - Table $\mathbf{1})$.

Among the 100 subjects, 30\% had noncompliance behavior (-Table 2).

- Table 3 shows the distribution of biochemical parameters of dialysis patients showing noncompliance behavior. The noncompliance behavior was assessed, and their biochemical parameters indicated that (43\%) had a high BUN level. All patients had low hemoglobin (Hb) levels. More than half of the subjects (67\%) had elevated serum potassium, (80\%) had high serum phosphate levels, and (93\%) of patients
Table 2 Distribution of noncompliance behavior score of dialysis patients

\begin{tabular}{|l|l|l|l|}
\hline $\begin{array}{l}\text { Behavior } \\
(\boldsymbol{n}=\mathbf{1 0 0})\end{array}$ & Score range & $\begin{array}{l}\text { Frequency } \\
(\boldsymbol{n})\end{array}$ & $\begin{array}{l}\text { Percentage } \\
(\%)\end{array}$ \\
\hline $\begin{array}{l}\text { Compliance } \\
\text { behavior }\end{array}$ & More than 850 & 70 & 70 \\
\hline $\begin{array}{l}\text { Noncompliance } \\
\text { behavior }\end{array}$ & Less than 850 & 30 & 30 \\
\hline
\end{tabular}

Table 3 Biological parameters of dialysis patients showing noncompliance behavior

\begin{tabular}{|l|l|l|}
\hline $\begin{array}{l}\text { Biological parameters } \\
(\boldsymbol{n}=30)\end{array}$ & Frequency $(\boldsymbol{n})$ & Percentage (\%) \\
\hline BUN & & \\
$2.5-7.1 \mathrm{mg} / \mathrm{dL}$ & 17 & 57 \\
$>7.1 \mathrm{mg} / \mathrm{dL}$ & 13 & 43 \\
\hline $\mathrm{Hb}$ & & \\
$<12 \mathrm{~g} / \mathrm{dL}$ & 30 & 100 \\
\hline Potassium & & \\
$3.5-5 \mathrm{mEq} / \mathrm{L}$ & 10 & 33 \\
$>5 \mathrm{mEq} / \mathrm{L}$ & 20 & 67 \\
\hline $\begin{array}{l}\text { Phosphorous } \\
2.5-4.5 \mathrm{mg} / \mathrm{dL}\end{array}$ & 6 & \\
$>4.5 \mathrm{mg} / \mathrm{dL}$ & 24 & 20 \\
\hline Albumin & & 80 \\
$<3.4 \mathrm{~g} / \mathrm{dL}$ & 2 & 7 \\
$3.4-5.4 \mathrm{~g} / \mathrm{dL}$ & 28 & 93 \\
\hline Weight gain & & \\
$2-4 \mathrm{Kg}$ & 27 & 90 \\
$>4 \mathrm{Kg}$ & 3 & 10 \\
\hline
\end{tabular}

had shown average serum albumin (Alb) levels. Among the 100 subjects, ( $7 \%$ ) had low serum albumin levels and $(90 \%)$ of the patients had interdialytic weight gain (IWG) between 2 and $4 \mathrm{~kg}$ and $10 \%$ had IWG more than $4 \mathrm{~kg}$.

The Karl Pearson correlation coefficient $(r)$ value of noncompliance behavior and biochemical parameters of CKD was $0.578(p<0.05)$. A significant positive correlation between noncompliance behavior and biochemical parameters was observed among the dialysis patients with CKD ( - Table 4 ).

\section{Discussion}

The present study showed that $30 \%$ of the subjects had noncompliance behavior. A study conducted by Lee et al

Table 4 Correlation between noncompliance and biological parameters

\begin{tabular}{|l|l|l|}
\hline Variables $(\boldsymbol{n}=\mathbf{3 0})$ & $\begin{array}{l}\text { Correlation } \\
(\boldsymbol{r} \text { value })\end{array}$ & $\begin{array}{l}\text { Level of } \\
\text { significance }\end{array}$ \\
\cline { 1 - 1 } $\begin{array}{l}\text { Noncompliance } \\
\text { behavior }\end{array}$ & 0.578 & $\begin{array}{l}0.01 \\
(p<0.05)\end{array}$ \\
\cline { 1 - 1 } Biological parameters & & \\
\hline
\end{tabular}


revealed that dietary and fluid compliance was observed among $35.5 \%$ and $40.3 \%$ of patients, respectively. ${ }^{17}$ Our study reported that $37.8 \%$ had compliance with diet and $42.6 \%$ had compliance with fluid. Kugler et al revealed that nonadherence to diet and fluid restrictions were $81.4 \%$ and $74.6 \%$, respectively. ${ }^{18}$ Ahrari et al reported that $41.1 \%$ of patients reported moderate nonadherence to diet, $45.2 \%$ reported moderate nonadherence to fluid. ${ }^{9}$ Contrary to the above studies, Bame et al reported that compliance with the diet regimen was $90 \%$ and $49.5 \%$ of patients were compliant with the fluid-restriction regimen in a hospital-based study. ${ }^{19}$ Such variations in the prevalence of dietary noncompliance or compliance may be accredited to the variations in the indicators and standards used for measuring compliance. In most of the studies in the past, dietary compliance was measured using serum $\mathrm{K}$ as the sole indicator. ${ }^{17}$ However, we used serum $\mathrm{K}, \mathrm{Alb}, \mathrm{Hb}$, and BUN parameters concurrently as an indicator of dietary compliance. Lee et al used serum $\mathrm{K}$ and phosphate levels as an indicator of dietary compliance. ${ }^{17}$

The serial values of biochemical measures serve as familiar sources of data to assess adherence to medications, diet and fluid restrictions, directly impacting the health outcomes. ${ }^{11}$ The current study showed that around $43 \%$ of patients had a high BUN level, $7 \%$ had low albumin levels, $67 \%$ had elevated serum potassium, and $90 \%$ had IWG between $2 \mathrm{~kg}$ and $4 \mathrm{~kg}$. A study has predicted that serum albumin levels as one of the sturdiest predictors in laboratories for mortality in dialysis patients as it indicates the nutritional status and the level of systemic inflammation. ${ }^{20}$ In the present study, out of $30 \%$ of dialysis patients showing noncompliance behavior, $28 \%$ of patients had serum albumin levels between 3.4 and $5.4 \mathrm{~g} / \mathrm{dL}$, which was slightly elevated. There was a strong association between comorbidity and hypoalbuminemia among dialysis patients. Furthermore, a tendency of decreased albumin concentration within 6 months prior to the patient's death was present. ${ }^{21}$

There was a positive correlation observed between noncompliance behavior and biochemical parameters among dialysis patients. Rambod et al had done a study to assess the factors of adherence in uremic patients on hemodialysis. BUN, serum potassium, serum phosphate levels, and IWG were collected and analyzed. There was a significant relationship between the biochemical parameters and IWG with educational status $(p \leq 0.05) .^{22}$

The study concludes that dietary compliance may be improved using nutritional counseling techniques and education, and motivating patients to modify and comply with dietary recommendations. The study findings have suggestions to all the healthcare workers, including clinicians, nurses, and all other medical staff in the dialysis unit, to promote counseling to the dialysis patients. This study was limited to hemodialysis patients, and the purposive sampling technique was used to select participants, which imposed limits in a larger generalization.

The present study shows that there is a significant relationship between noncompliance behavior and biochemical parameters. To improve the compliance behavior among these patients, nurses have to be empowered as counselors, providing health education and counseling the patients on proper diet, fluid intake, and maintaining health-compliance behavior. Based on the current study, a researcher can develop further studies to progress toward new problemsolving and preventive strategies.

\section{Conclusion}

Noncompliance among dialysis patients is a significant problem even though it is said to be inversely related to survival rates. Hemodialysis requires patients to commit considerable time to their treatment, comply with strict dietary and fluid restrictions, and take medication regularly. This study reveals a significant relationship between the noncompliance behavior and biochemical parameters of CKD patients. Periodic counseling and constant motivation can improve patients' confidence in fluid, dietary, and medication compliance leading to a healthy life.

\section{Funding}

This study received funding from Nitte (Deemed to be University) and the grant number was NUSR2/2018/ 10/70.

\section{Conflict of Interest}

None declared.

\section{Acknowledgments}

The authors would like to thank all the CKD patients undergoing hemodialysis who participated in this study. We want to thank K. S, Hegde Medical Academy (KSHEMA) hospital, dialysis centers in Karkala and Puttur, Nitte Usha Institute of Nursing Sciences, and Nitte (Deemed to be University) for their support.

\section{References}

1 Weis L, Metzger M, Haymann J-P, et al; NephroTest Study Group. Renal function can improve at any stage of chronic kidney disease. PLoS One 2013;8(12):e81835. Doi: 10.1371/journal.pone.008183

2 Krans B. Dialysis. 2019. Accessed November 1, 2021 at: www. healthline.com/health/dialysis

3 Mollaoğlu M. Quality of life in patients undergoing hemodialysis. Chapter 37. Intech Open; 2013:823-843. Available at: http://dx. doi.org/10.5772/45929

4 Chandrashekar A, Ramakrishnan S, Rangarajan D. Survival analysis of patients on maintenance hemodialysis. Indian J Nephrol 2014;24(04):206-213

5 Wolcott DL, Maida CA, Diamond R, Nissenson AR. Treatment compliance in end-stage renal disease patients on dialysis. Am J Nephrol 1986;6(05):329-338

6 Loghman-Adham M. Medication noncompliance in patients with chronic disease: issues in dialysis and renal transplantation. Am J Manag Care 2003;9(02):155-171

7 Leggat JE Jr, Orzol SM, Hulbert-Shearon TE, et al. Noncompliance in hemodialysis: predictors and survival analysis. Am J Kidney Dis 1998;32(01):139-145

8 Lentine K, Wrone EM. New insights into protein intake and progression of renal disease. Curr Opin Nephrol Hypertens 2004;13(03):333-336 
9 Ahrari S, Moshki M, Bahrami M. The relationship between social support and adherence of dietary and fluids restrictions among hemodialysis patients in Iran. J Caring Sci 2014;3(01):11-19

10 Beerendrakumar N, Ramamoorthy L, Haridasan S. Dietary and fluid regime adherence in chronic kidney disease patients. J Caring Sci 2018;7(01):17-20

11 Arici M, Altun B, Usalan C, et al. Compliance in hemodialysis patients: unanticipated monitoring of biochemical indices. Blood Purif 1998;16(05):275-280

12 Ferraro KF, Dixon RD, Kinlaw BJR. Measuring compliance among in-center hemodialysis patients. Dial Transplant 1986; 15:226-236

13 Simmens S, Kimmel PL, Kobrin S, Reiss D. Multidimensional assessment of compliance in two dialysis units. J Am Soc Nephrol $1991 ; 2: 351$

14 Blackburn SL. Dietary compliance of chronic hemodialysis patients. J Am Diet Assoc 1977;70(01):31-37

15 Hitchcock PB, Brantley PJ, Jones GN, McKnight GT. Stress and social support as predictors of dietary compliance in hemodialysis patients. Behav Med 1992;18(01):13-20
16 Kim Y, Evangelista LS, Phillips LR, Pavlish C, Kopple JD. The EndStage Renal Disease Adherence Questionnaire (ESRD-AQ): testing the psychometric properties in patients receiving in-centerhemodialysis. Nephrol Nurs J. 2010;37(04):377-393

17 Lee SH, Molassiotis A. Dietary and fluid compliance in Chinese hemodialysis patients. Int J Nurs Stud 2002;39(07):695-704

18 Kugler C, Vlaminck H, Haverich A, Maes B. Nonadherence with diet and fluid restrictions among adults having hemodialysis. J Nurs Scholarsh 2005;37(01):25-29

19 Bame SI, Petersen N, Wray NP. Variation in hemodialysis patient compliance according to demographic characteristics. Soc Sci Med 1993;37(08):1035-1043

20 Yeun JY, Kaysen GA. Factors influencing serum albumin in dialysis patients. Am J Kidney Dis 1998;32(6, Suppl 4)S118-S125

21 Kaysen GA. Serum albumin concentration in dialysis patients: why does it remain resistant to therapy? Kidney Int Suppl 2003; 64(87):S92-S98

22 Rambod M, Peyravi H, Shokrpour N, Sareban MT. Dietary and fluid adherence in Iranian hemodialysis patients. Health Care Manag (Frederick) 2010;29(04):359-364 